OPEN ACCESS

Edited by:

Francois Galgani,

French Research Institute for Exploitation of the Sea (IFREMER),

France

Reviewed by:

Jongmyoung Lee,

Our Sea of East Asia Network,

South Korea

Mikaël Kedzierski,

FRE3744 Institut de Recherche Henri

Dupuy de Lôme (IRDL), France

${ }^{*}$ Correspondence:

Kathryn A. Willis

kathy.willi@@csiro.au

Specialty section:

This article was submitted to

Marine Pollution,

a section of the journal

Frontiers in Marine Science

Received: 12 October 2017 Accepted: 07 December 2017 Published: 19 December 2017

Citation:

Willis $K A$, Eriksen $R$, Wilcox $C$ and Hardesty BD (2017) Microplastic Distribution at Different Sediment

Depths in an Urban Estuary.

Front. Mar. Sci. 4:419.

doi: 10.3389/fmars.2017.00419

\section{Microplastic Distribution at Different Sediment Depths in an Urban Estuary}

\author{
Kathryn A. Willis ${ }^{1,2 *}$, Ruth Eriksen ${ }^{1,3}$, Chris Wilcox $^{1}$ and Britta D. Hardesty ${ }^{1}$ \\ ${ }^{1}$ Oceans and Atmosphere, Commonwealth Scientific and Industrial Research Organisation, Hobart, TAS, Australia, ${ }^{2}$ School \\ of Social Sciences, College of Arts, Law and Education, University of Tasmania, Hobart, TAS, Australia, ${ }^{3}$ Institute for Marine \\ and Antarctic Studies, University of Tasmania, Hobart, TAS, Australia
}

As plastic production increases, so to do the threats from plastic pollution. Microplastics (defined as plastics $<5 \mathrm{~mm}$ ) are a subset of marine debris about which we know less than we do of larger debris items, though they are potentially ubiquitous in the marine environment. To quantify the distribution and change in microplastic densities through time, we sampled sediment cores from an estuary in Tasmania, Australia. We hypothesized that the type, distribution and abundance of microplastics observed would be associated with increasing plastic production, coastal population growth, and proximity to urban water outflows and local hydrodynamics. Sediments ranging from the year 1744 to 2004 were sub-sampled from each core. We observed microplastics in every sample, with greater plastic frequencies found in the upper (more recent) sediments. This time trend of microplastic accumulation matched that of global plastic production and coastal population growth. We observed that fibers were the most abundant type of microplastic in our samples. These fibers were present in sediments that settled prior to the presence of plastics in the environment. We propose a simple statistical model to estimate the level of contamination in our samples. We suggest that the current trend in the literature suggesting very high loads of fibers, particularly in remote locations such as the deep seafloor, may be largely due to contamination.

Keywords: core samples, estuary, microplastics, plastic fibers, sediment

\section{INTRODUCTION}

Microplastics (plastics $<5 \mathrm{~mm}$, Arthur et al., 2008) have been observed throughout bottom sediments of marine and freshwater environments, including sediments in rivers (Casta-eda et al., 2014), estuaries (Thompson et al., 2004; Sruthy and Ramasamy, 2017), lagoons (Vianello et al., 2013), lakes (Corcoran et al., 2015), seas (Zobkov and Esiukova, 2017), and deep sea trenches (Van Cauwenberghe et al., 2013; Woodall et al., 2014; Fischer et al., 2015). Microplastics are commonly found in the environment in three forms; fragments which form from mechanical and biological fragmentation of larger plastic items (ter Halle et al., 2016), microbeads which are manufactured as abrasives in cosmetics and air-blasting (Fendall and Sewell, 2009; Mason et al., 2016), and microfibers from sources such as synthetic fabrics and ropes (Browne et al., 2011). Studies have shown multiple damaging effects of microplastics in the environment, including adsorption of toxic organic contaminants (Endo et al., 2005; Teuten et al., 2007; Rochman et al., 2013), ingestion by animals with implications for human consumption (Van Cauwenberghe and Janssen, 2014; Rochman et al., 2015) and changing the heat transfer and water movement of sediment (Carson et al., 2011). 
Microplastics have been observed in benthic environments since the late 1970s (Gregory, 1977; Shiber, 1979) and sediments are suggested to be a long-term sink for microplastics (MorétFerguson et al., 2010; Cózar et al., 2014). Benthos is an important feeding environment for many marine species (Anderson and Lovvorn, 2008; MacDonald et al., 2012; Gittman and Keller, 2013) and a recent study has shown marine benthic species ingest microplastics (Courtene-Jones et al., 2017). Knowledge of the harmful effects of microplastics on benthic marine species and communities is growing (Green, 2016; Galloway et al., 2017), however, little is known of past microplastic accumulation in benthic environments.

Several studies have examined microplastics in sediments (Claessens et al., 2011; Corcoran et al., 2015; Klein et al., 2015). For example, Claessens et al. (2011) quantified the number of microplastics in 16 year old sediments collected at the intertidal and high water mark. However, there have been no evaluations of microplastic contamination in deep sediments with known age cores, allowing analysis of deposition rates and concentrations. To address this knowledge gap, we compared sediment cores taken from an urbanized estuary and asked the following questions: Do microplastic densities change in time (with known age of sediment cores)? If microplastics are present, do we detect different densities as we move further from areas of higher human population densities?

\section{MATERIALS AND METHODS}

\section{Sampling Location}

Core samples were taken from Elwick Bay and Dogshear Point in the Derwent Estuary, Tasmania, Australia (Figure 1). The area is classed as urban/light industrial and the shoreline is partially reclaimed land. Surrounding land use includes residential areas, a horse race course and stables, low lying recreational areas, a high school and an entertainment estate. A major highway also runs adjacent along both shores. Two urban rivulets, Humphreys and Barossa, which exit at Elwick Bay, pass through urban areas in their lower reaches. Both have gross pollutant traps that trap anthropogenic debris that is larger than $10-15 \mathrm{~cm}$ in diameter. Sedimentation rates in Elwick Bay range from 0.4 to $0.5 \mathrm{~cm}$ per year, to a higher rate of $0.7 \mathrm{~cm}$ per year during a major flood or erosional event (Townsend and Seen, 2012).

Cores were collected in November 2004 as outlined in Townsend and Seen (2012). Core A was taken from the middle region of Elwick Bay around $3 \mathrm{~km}$ upstream of a zinc refinery (Townsend and Seen, 2012). Core B was taken off Dogshear Point, $3 \mathrm{~km}$ north-east of core A. Each core was sliced into $2 \mathrm{~cm}$ sections and stored in sealed containers. Core samples were stored refrigerated upright until analysis. A total of seven, $2 \mathrm{~cm}$ section samples from each core were processed and analyzed. Samples were systematically selected at different depth intervals of the core, with a maximum sample depth of $104 \mathrm{~cm}$. This allowed us to analyse the samples in a temporal fashion, as deeper samples are from older sediments.

\section{Aging Sediment Core Samples}

A duplicate of core A was aged using lead isotopes (Townsend and Seen, 2012). Using the sedimentation rates and ages calculated in Townsend and Seen (2012) the age of sediment sections analyzed in this study were inferred. Sediments between 0 and $10 \mathrm{~cm}$ took 21 years to settle at a rate of $0.48 \pm 0.05 \mathrm{~cm} / \mathrm{yr}^{-1}$ with sediments at $10 \mathrm{~cm}$ aged at $1983 \pm 2$. Sediments between 10 and $30 \mathrm{~cm}$ settled at a rate of $0.69 \mathrm{~cm} / \mathrm{yr}^{-1}$ with sediments at $30 \mathrm{~cm}$ aged at $1954 \pm 5$. Sediments between 30 and $50 \mathrm{~cm}$ took 46 years to settle at a rate of $0.43 \pm 0.07 \mathrm{~cm} / \mathrm{yr}^{-1}$ with sediments at $50 \mathrm{~cm}$ aged at 1908 (Townsend and Seen, 2012).

\section{Laboratory Analysis}

Sample processing was adapted from Reeves et al. (2016). In brief, samples were processed using a stepwise approach include sieving, organic material digestion, density separation, centrifuging, and filtration to separate microplastics from the bulk sediment. All laboratory work was conducted under a vacuum hood and exposed samples and equipment were covered with foil to prevent contamination from airborne microplastics. Natural fiber clothing and laboratory coats were worn throughout the analysis to reduce microplastic contamination from synthetic clothing.

\section{Sieving}

Each sample was placed in a beaker with deionized water and agitated with a metal spatula to disassociate large clumps of sediment. The contents of the beaker were then poured through a sieve stack. Sieves were stacked sequentially according to mesh size, with the largest mesh size at the top. Each sieve was rinsed with deionised water and left to dry.

\section{Organic Material Digestion}

Each dried sample was placed in a beaker with $20 \mathrm{ml}$ of $30 \%$ hydrogen peroxide, $20 \mathrm{ml}$ of $0.05 \mathrm{M}$ iron (II) solution and a magnetic stir bar. The sediment solution was left at room temperature for $5 \mathrm{~min}$, then was placed on a heating magnetic stirrer and heated to $75^{\circ} \mathrm{C}$ for $30 \mathrm{~min}$. If organic material was visible after $30 \mathrm{~min}, 20 \mathrm{ml}$ of hydrogen peroxide was added every $15 \mathrm{~min}$ and stirring/heating continued until all visible organic material was digested.

\section{Density Separation, Centrifuging, and Filtration}

Each digested sample was placed in a $50 \mathrm{ml}$ centrifuge tube. Large sediment samples were split evenly between two tubes. Sodium iodide (NaI) solution (density 1.6-1.8 g.ml) was added to each tube until $30 \mathrm{ml}$ of $\mathrm{NaI}$ was overlaying the sediment sample. Each tube was capped, shaken manually for $20 \mathrm{~s}$ and then placed in a benchtop centrifuge for $5 \mathrm{~min}$ at 3,500 revolutions per minute. Tubes were removed gently to minimize sediment re-suspension. The top $10 \mathrm{ml}$ of supernatant $\mathrm{NaI}$ solution was poured off into a glass Büchner vacuum apparatus fitted with a $1.2 \mu \mathrm{m}$ polycarbonate membrane filter. The remaining sediment in the tube was topped up with $\mathrm{NaI}$, so $30 \mathrm{ml}$ was overlaying the sediment. The sediment then underwent the previously described treatment of manual shaking, centrifuging, and filtering of supernatant, twice. A 


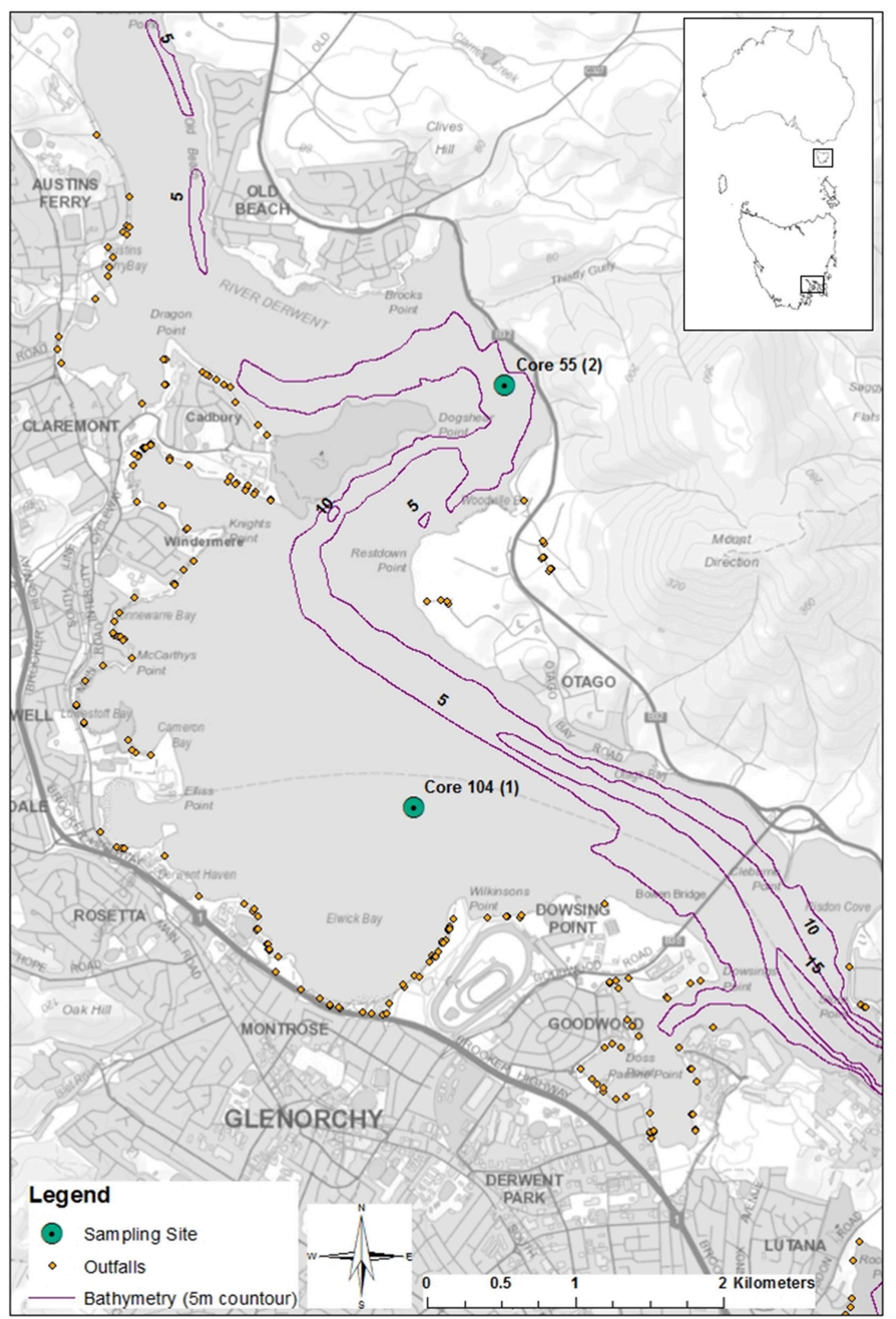

FIGURE 1 | Core sample locations in the Derwent Estuary, Tasmania, Australia. River flows north to south. Generated by Kathryn Willis using ArcGIS, [Desktop version 10.2], (https://www.arcgis.com/features/index.html). Bathymetry from Lucieer (2007), SeaMap Tasmania Bathymetric Data. Tasmanian Aquaculture and Fisheries Institute. Data accessed at http://metadata.imas.utas.edu.au/geonetwork/srv/eng/metadata.show?uuid=fa2dbc70-44ab-11dc-8cd0-00188b4c0af8 on 27/04/2017. 
total of three supernatants, per sample, were poured into the vacuum apparatus and filtered. To ensure all possible separated microplastics were poured on the filter paper, on the last round of treatment (i.e., the third round), the total supernatant $\mathrm{NaI}$ solution was poured into the vacuum apparatus. The Büchner funnel and $1.2 \mu \mathrm{m}$ filter were then rinsed with deionised water to capture any microplastics that may have adhered to the glass during filtration. All filtered samples were stored individually in sealed petri-dishes until microscope analysis.

\section{Microscope Analysis}

Filtered samples were analyzed for microplastic content using a stereomicroscope (magnification $\times 40$ ). Each sample was divided into seven sorting sections using a fine-point metal probe. Samples were observed for 15 min using a constant magnification setting. Following the "Guidelines for Microscope Inspection" (Masura et al., 2015) an object was identified as plastic if it held shape or stretched when rubbed/pressed with a metal probe. Organic material would break a part under the above treatment. Positively identified microplastics were sorted into four categories according to their shape and texture (Table 1).

\section{Deposition Trend}

We tested whether the rate of micro fiber deposition observed in the cores correlated with plastic production using linear regression. We used the time trend in global plastic production values (PlasticsEurope, 2016) as a proxy for the relative time trend in production in the Derwent estuary. We used an exponential mode 1 to fit to the data available on global production to estimate the proportional change on an annual basis since plastic went into commercial production in the mid 1900s.

We adjusted our trend estimate for contamination by assuming the contamination rate was constant with respect to depth of the core slice. Based on this assumption the intercept term of the linear regression of microfiber concentration on plastic production change is an estimate of the contamination rate in the samples. The concentration of fibers in sediment slices from before 1950 serves as a second estimate of the contamination rate, as these sediments were deposited prior to the availability of plastic in the environment. The slope of the relationship between microfiber concentration and plastic production gives an estimate of the proportional increase in

TABLE 1 | List of features used to identify different microplastic categories.

\begin{tabular}{llll}
\hline $\begin{array}{l}\text { Microplastic } \\
\text { category }\end{array}$ & Shape & Texture & Color \\
\hline Fiber & $\begin{array}{l}\text { String-like with } \\
\text { irregular bends }\end{array}$ & Soft, malleable & Any \\
Sheet & Thin, flat & Soft, malleable & $\begin{array}{l}\text { Often clear, black, } \\
\text { or translucent blue }\end{array}$ \\
Fragment & Thin, flat & Hard, rigid & $\begin{array}{l}\text { Often black or red } \\
\text { Bead }\end{array}$ \\
Spherical, smooth & Hard & $\begin{array}{l}\text { Often black or } \\
\text { brown }\end{array}$
\end{tabular}

plastic in sediments, per unit of increase in production, which can be interpreted as the leakage rate from production.

We only used micro fiber values in the analysis as micro fibers made up nearly $90 \%$ of all microplastics in the cores.

\section{RESULTS}

Microplastics were observed in every sediment sample of both cores $(N=14)$. A total of 211 microplastics were observed in core $\mathrm{A}(N=7)$, and 252 microplastics were observed in core $\mathrm{B}(N=7)$. The mean weight of dry sediment samples was $63.36 \mathrm{~g}$ for core $\mathrm{A}$ and $52.36 \mathrm{~g}$ for core $\mathrm{B}$ with a mean of 2.43 plastic fragments per gram of sediment for core A and 4.2 plastic fragments per gram of sediment for core B. Microplastics mainly occurred as fibers ( $87 \%$ of total items observed), followed by sheet (9\%), fragment (3\%), and beads (1\%) (Figure 2). A control sample, i.e., conducting the laboratory method without a sediment sample, presented a maximum of eight microplastic fibers (range $=0-8$ ).

\section{Size Classes of Microplastics Detected}

In both cores, the frequency of microplastics increased with a decrease in size class. In core A, 137 microplastics were observed in size class $63 \mu \mathrm{m}, 49$ in size class $100 \mu \mathrm{m}, 24$ in size class $1 \mathrm{~mm}$, and 1 in size class $4 \mathrm{~mm}$ (Figure 3 ). In core B, 132 microplastics were observed in size class $63 \mu \mathrm{m}, 93$ in size class $100 \mu \mathrm{m}$, and 27 in size class $1 \mathrm{~mm}$ (Figure 3). In core A an unusually high number of microplastics were observed in sample 7 .

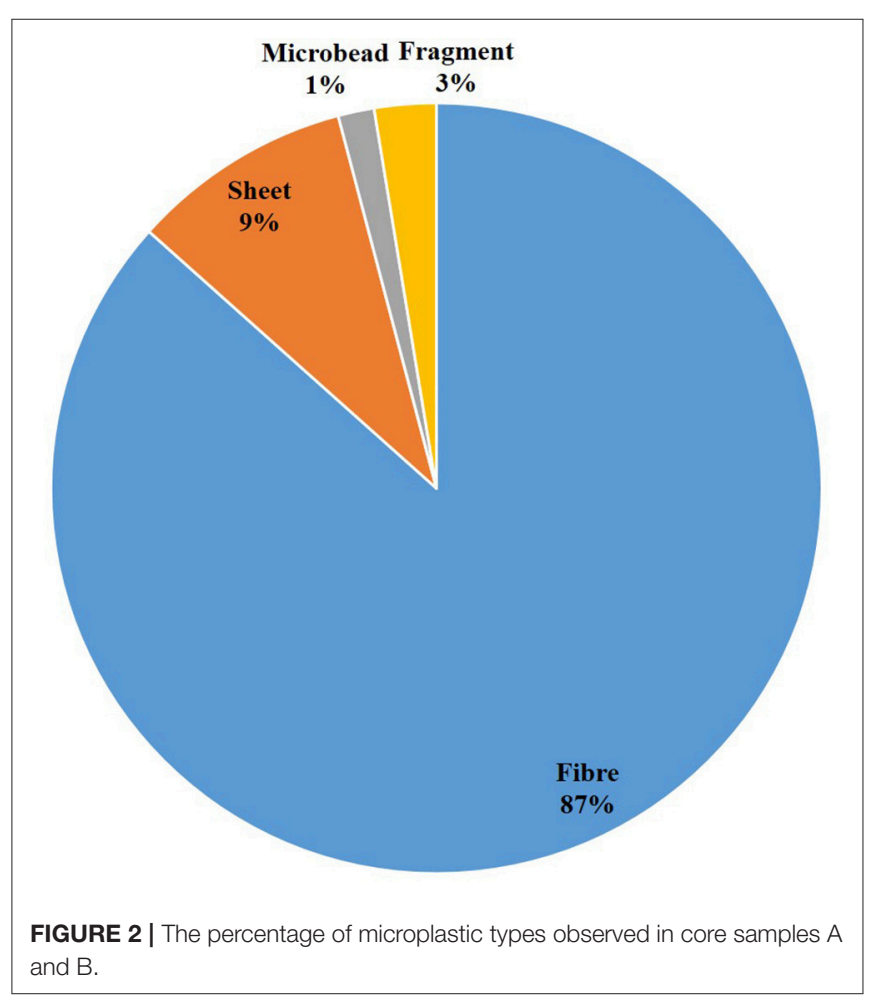




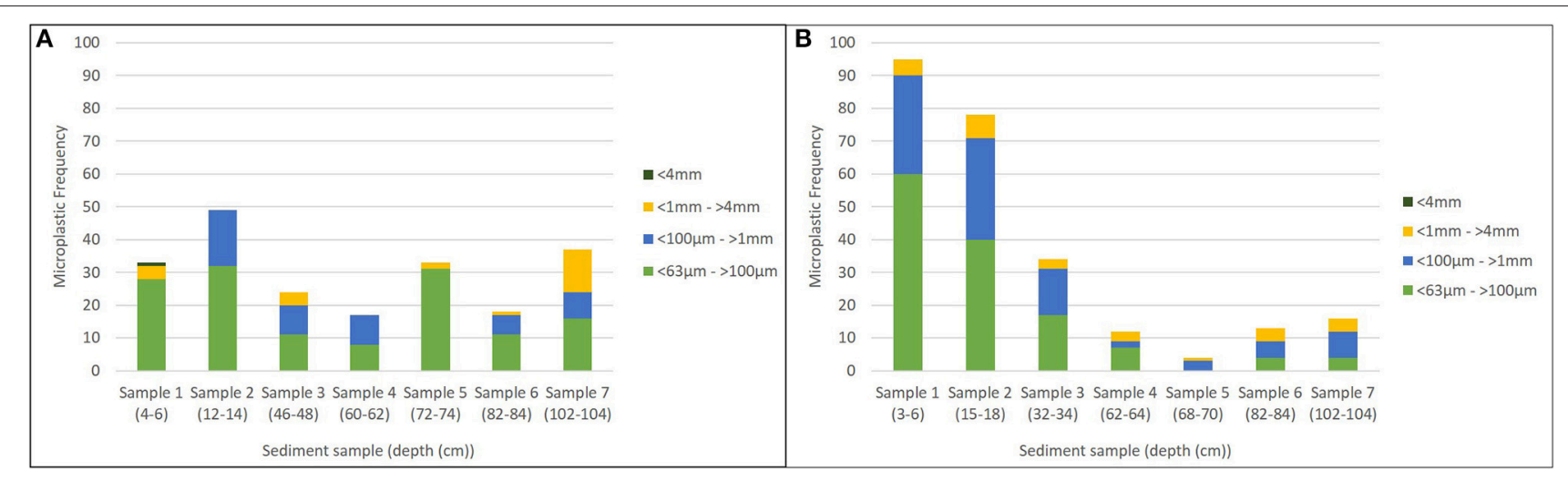

FIGURE 3 | The number of microplastics in each size class for core samples $(\mathbf{A}, \mathbf{B})$.

\section{Depth}

In each core, we found more microplastics in the upper layer of sediments (more recent) than in the deeper (older) sediments. In core A, $38.9 \%$ of microplastics were observed in sample 1 and sample 2 depth classes, whereas only $26.1 \%$ of all microplastics were observed in the deeper layers (samples 6 and 7). In core B, we found $68.7 \%$ of microplastics in the upper, more recent layers (sample 1 and sample 2) whereas only $11.5 \%$ of microplastics were observed in the deeper layers (samples 6 and 7). Smaller microplastics were more common in shallower samples (i.e., there were more microplastics in the smallest size class $(<63 \mu \mathrm{m}-100 \mu \mathrm{m})$ in sample 1 than in sample 7 (Figure 3). In core A, 20.4\% of all $63 \mu \mathrm{m}$ microplastics were observed in sample 1 whereas only $11.7 \%$ in sample 7 . In core B, $45.5 \%$ of all $63 \mu \mathrm{m}$ microplastics were observed in sample 1 whereas only $3.0 \%$ in sample 7.

\section{Deposition Trend}

The number of micro fibers was higher in the shallower (younger) sediment samples. The rate of micro fiber deposition in the sediment correlated strongly with the expected change in production in the study region, based on the annual global plastic production (Figure 4; Table 2). The predicted accumulation model was a better model than the null (AIC: Predicted $=101$, Null =112). As global plastic production increased, the number of micro fibers deposited in sediments significantly increased $(p=<0.05)$.

\section{DISCUSSION}

We observed more microplastics in the upper sediments. In core $\mathrm{B}$ there were six times more microplastics present in the top $15 \mathrm{~cm}$ (1976 and younger) than in the bottom $22 \mathrm{~cm}$ (1799 and older). In core A there were one and a half times the number of microplastics in the top $10 \mathrm{~cm}$ (1983 and younger) than in the bottom $22 \mathrm{~cm}$ (1799 and older). This observation is likely due to the exposure of upper sediments to a higher proportion of microplastics settling out from the water column. The production

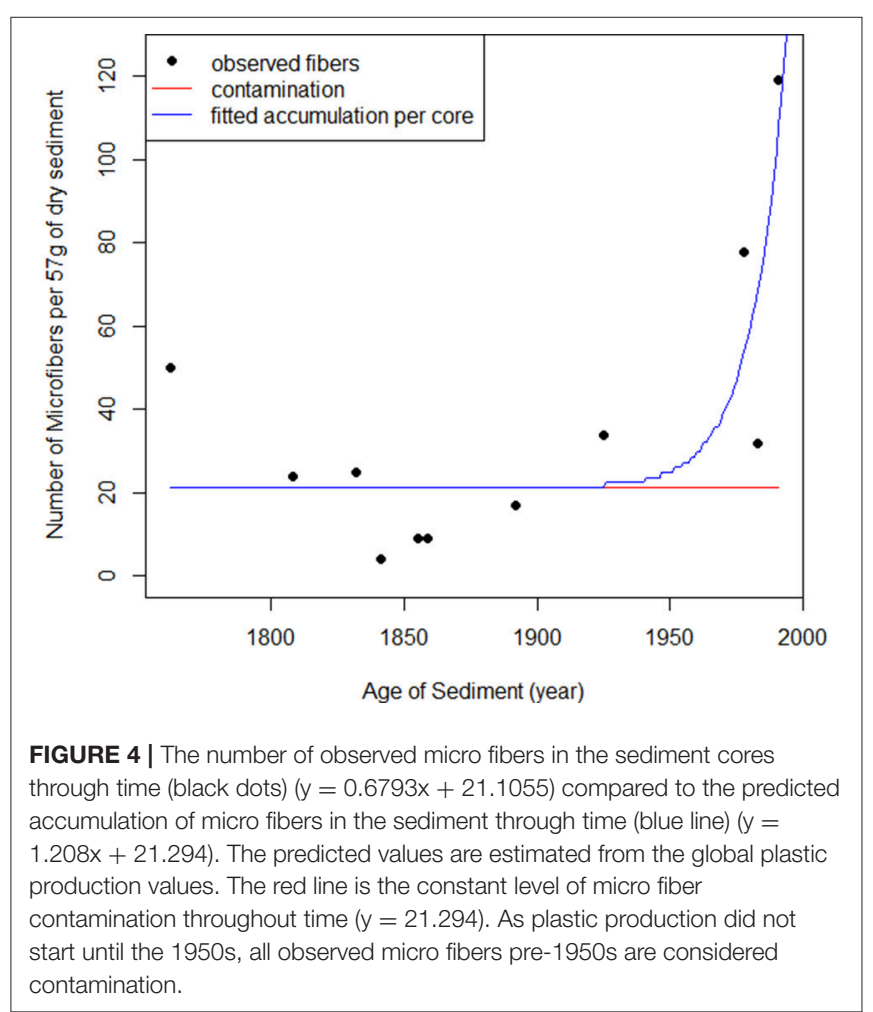

of plastics has increased from 100 million tons per year in 1993 to 322 million tons per year in 2015 (PlasticsEurope, 2008, 2016).

The environments for our sediment cores differed; core B was taken $150 \mathrm{~m}$ off shore from a relatively high energy position in a deep channel, whereas core A was taken $1,000 \mathrm{~m}$ off shore in a large shallow bay with low energy and more rapid sedimentation (Figure 1). Despite the normal low energy dynamics of site core A, it is occasionally subject to the passage of large floods. This scours the embayment with fresh water and greatly changes the potential sources of microplastic contamination for short periods of time. These differences in site conditions could explain the higher concentration of plastics at site B. The site is not subject to large scouring events, thus any deposition is likely 
TABLE 2 | Results from the model of predicted accumulation of micro fibers in sediment through time.

\begin{tabular}{llccc}
\hline Model & Terms & Estimate & $\boldsymbol{P}$-value & AIC \\
\hline Predicted & Number of fibers & 21.2944 & 0.01329 & 101.0587 \\
Accumulation & Plastic production estimate & 1.2084 & 0.00142 & \\
\hline Null & Number of fibers & 36.45 & 0.00578 & 112.1359 \\
\hline
\end{tabular}

to remain in place. In addition, the site is much closer to sewage and stormwater outfall drains, which we found to be sources of plastic pollution in previous work (Willis et al., 2017). This result is similar to those found in other studies, which found higher numbers of plastics at sites closer to storm drain outfalls (Duckett and Repaci, 2015; Horton et al., 2017).

Most microplastics observed were fibers (87\%). This phenomenon has been observed in other sediment analyses (MONAS, 2014; Woodall et al., 2015; Zobkov and Esiukova, 2017). Browne (2015) suggests microplastic fibers found in marine habitats may be derived from sewage as consequence of washing clothes. Furthermore, up to 1,770 microplastics have been reporting to leave a waste water treatment plant in effluent water per hour (Magnusson and Norén, 2014). As many outflows enter the Derwent Estuary, they are a probable source for the large quantity of microfibers observed in the samples. Outfalls as a source of micro fibers in the marine environment also indicates the dispersion from source to point of deposition is relatively local.

The strong correlation between the observed micro fibers and the predicted change in plastic production (Figure 4) indicates there is a clear temporal trend in micro fiber deposition in sediments (Table 2). This suggests that as plastic production increases, microplastic pollution is increasing proportionately. This is likely due to an increase in plastic leakage from the waste stream, as has been reported elsewhere (Thompson et al., 2009). The increase in coastal populations has been observed to increase the amount of pollution entering waterways (Jambeck et al., 2015; Lebreton et al., 2017). For example, $40 \%$ of Tasmania's population lives around the margins of the Derwent Estuary, with the population doubling between 1950 and 2015 (Carver, 1954; Coughanowr et al., 2015). Hence, older deeper sediments were exposed to an environment with markedly lower population and plastic production rate and less opportunity for plastic contamination than the younger, shallower sediments. This pattern was also observed on Belgian beaches where plastic pollution in sediments had tripled over 20 years (Claessens et al., 2011).

Our results demonstrate micro fibers are present in marine sediments that settled pre-plastic production. Microplastics have been recorded in marine sediments since the 1970s (Gregory, 1977; Shiber, 1979). We expected to only observe microplastics in sediments shallower than $30 \mathrm{~cm}$, as the sediments were aged to be younger than $1954 \pm 5$ years (Townsend and Seen, 2012). However, we observed micro fibers down to $104 \mathrm{~cm}$. Sediment accumulation rates in Elwick Bay range from 0.4 to $0.7 \mathrm{~cm}$ per year (Townsend and Seen, 2012). Hence, sediment at $104 \mathrm{~cm}$ would have settled between 149 and 260 years ago (i.e., in 1855 to 1744). Observing micro fibers down to $104 \mathrm{~cm}$ does not indicate that microplastics have been settling in sediment for 260 years. Rather it raises concerns that the sediment cores were exposed to micro fiber contamination either during collection or analysis. We calculated the mean frequency of fibers in our samples pre1950s (i.e., plastic production) to estimate the fraction of fibers from both field and laboratory contamination, which yielded an estimate of up to 17.2 fibers $(\sim 60 \%)$ per sediment sample due to contamination, which is in line with the estimate of 21 fibers per sample, based on the intercept term in our linear regression (Figure 4). As the exact date that plastic production commenced in the Derwent Estuary is not known the values from the predicted model will give a better estimation of past microplastic levels in the sediment of the Derwent Estuary.

The fine structure of microplastics could enable them to move deeper into the older sediment via mixing due to bioturbation or water flows e.g., storm/flood events and direct transport by animals. This downward transport should affect all microplastic types, however, we only found micro fibers in the older sediment. The high number of fibers observed in the laboratory blanks indicates that the preventative contamination measures employed during laboratory analysis were ineffective. As we were unable to conduct our microscope analysis under a fume hood, airborne fibers could be one point of sample contamination. It is also possible that contamination occurred during the field collection and slicing of the cores. The cores were not originally collected for microplastic analysis. Hence, methods to prevent microplastic contamination were not a component of the field sampling program. We suspect contamination from researcher's clothing and equipment (i.e., synthetic fibers from rope fragmentation; Thompson et al., 2004) or from airborne microplastics (Dris et al., 2015) as the most likely contamination sources. This points to a major issue with the common opportunistic use of sediment samples to look for microplastics in deep sea sediments and other places. The opportunistic nature of sampling questions whether adequate procedures to prevent microplastic contamination were undertaken. Samples in this study and others should be interpreted with contamination in mind as the results showed 20 micro fibers per $50 \mathrm{~g}$ of sediment can be due to contamination alone.

Considerably fewer sheet, fragment, and bead microplastics were observed than fibers $(13 \%$ for these three categories combined). These non-fiber plastics were all observed in the upper sediment layers which suggests there was no contamination issue for these materials. The lower counts of nonfiber microplastics could indicate these microplastics are not a common contaminant in estuaries. However, observer bias is also a likely explanation. Microfibers may be more conspicuous under a microscope due to their unique irregular bent filament shape and commonly settling on top of the other filtered particles (i.e., sediment granules, undigested biological matter, diatom shells). Sheet, fragment, and bead microplastics may be harder to detect as their shapes were more similar to those of undigested plant material and sediment granules. Hence, they could be underrepresented in counts from sediment cores. 
We found size class $63 \mu \mathrm{m}$ had the highest count of microplastics in every sample but one. Eighty-five percent of sediments in Elwick Bay are $<63 \mu \mathrm{m}$ (Koehnken and Eriksen, 2004), reflecting a highly organically enriched depositional area. As both sediments and microplastics are a similar size, it can be inferred that the same forces act on sediment accumulations and microplastics accumulation (Vianello et al., 2013). The high frequency of $63 \mu \mathrm{m}$ microplastics in sediments is quite different to the size distribution observed from net trawls of the ocean surface. In net trawls, small microplastics (i.e., 100 to $63 \mu \mathrm{m}$ ) are not observed even though they are likely present on the surface (Law et al., 2010; Eriksen et al., 2013). This discrepancy in microplastic sizes may be largely due to the difference in sample analysis (e.g., visual versus microscope identification) (van Sebille et al., 2015) as it would be unlikely or impossible to observe microplastics between 100 and $63 \mu \mathrm{m}$ solely scanning with the naked eye.

\section{CONCLUDING REMARKS}

Our study shows that sediments are a useful record of past and present plastic leakage from the waste stream into the marine environment. This is not unlike samples from other parts of the marine ecosystems, including the water column (van Sebille et al., 2015), seabirds (Wilcox et al., 2015), and turtles (Schuyler et al., 2014). Microplastics were present in all samples, even in sediments dated from pre-plastic production. Based on our estimates, current microplastic concentrations in sediment are 115 microplastics, and are increasing at an accelerated rate of 1.208 microplastics per year. Generally speaking, however, the frequency of plastics corresponded with the increase in

\section{REFERENCES}

Anderson, E. M., and Lovvorn, J. R. (2008). Gray whales may increase feeding opportunities for avian benthivores. Mar. Ecol. Prog. Ser. 360, 291-296. doi: 10.3354/meps07359

Arthur, C., Baker, J., and Bamford, H. (2008). International Research Workshop on the Occurrence, Effects, and Fate of Microplastic Marine Debris.

Browne, M. A. (2015). "Sources and pathways of microplastics to habitats," in Marine Anthropogenic Litter, eds M. Bergmann, L. Gutow, and M. Klages (Cham: Springer International Publishing), 229-244.

Browne, M. A., Crump, P., Niven, S. J., Teuten, E., Tonkin, A., Galloway, T., et al. (2011). Accumulation of microplastic on shorelines woldwide: sources and sinks. Environ. Sci. Technol. 45, 9175-9179. doi: 10.1021/es201811s

Carson, H. S., Colbert, S. L., Kaylor, M. J., and McDermid, K. J. (2011). Small plastic debris changes water movement and heat transfer through beach sediments. Mar. Pollut. Bull. 62, 1708-1713. doi: 10.1016/j.marpolbul.2011.05.032

Carver, S. R. (1954). "Part I Tasmania: analysis of population in local government areas," in Statistics, ed CBOCA (Canberra, Australia: Commonwealth Bureau of Census and Statistics), 1-71.

Casta-eda, R. A., Avlijas, S., Simard, M. A., Ricciardi, A., and Smith, R. (2014). Microplastic pollution in St. Lawrence River sediments. Can. J. Fish. Aquatic Sci. 71, 1767-1771. doi: 10.1139/cjfas-2014-0281

Claessens, M., De Meester, S., Van Landuyt, L., De Clerck, K., and Janssen, C. R. (2011). Occurrence and distribution of microplastics in marine sediments along the Belgian coast. Mar. Pollut. Bull. 62, 2199-2204. doi: 10.1016/j.marpolbul.2011.06.030

Corcoran, P. L., Norris, T., Ceccanese, T., Walzak, M. J., Helm, P. A., and Marvin, C. H. (2015). Hidden plastics of Lake Ontario, Canada and their plastic production and coastal populations. The presence of microplastics in the older sediments indicates there was possible contamination during sampling or laboratory analysis, which is an element that must be carefully considered when estimating microplastics loads and their presumed ubiquity in the marine environment.

\section{AUTHOR CONTRIBUTIONS}

$\mathrm{BDH}$ and $\mathrm{CW}$ : designed the study; KAW: completed laboratory work and wrote original draft, with contributions by other authors; $\mathrm{BDH}$ and RE: provided technical advice and support for laboratory work; RE: collected the samples; CW: completed data manipulation, statistical analyses, and provided technical expertise on manuscript.

\section{FUNDING}

All authors were funded by CSIRO Oceans and Atmosphere, Tasmania, Australia.

\section{ACKNOWLEDGMENTS}

The sediment cores for this study were made available by the Derwent Estuary Program, as part of the Coastal Catchments Initiative, and we thank Christine Coughanowr and Mike Rushton. We would like to thank Simon Reeves for providing laboratory space and training researchers in the microplastics sampling methodology used in this work. We thank CSIRO Oceans and Atmosphere for supporting this work.

potential preservation in the sediment record. Environ. Poll. 204, 17-25. doi: 10.1016/j.envpol.2015.04.009

Coughanowr, C., Whitehead, S., Whitehead, J., Einoder, L., Taylor, U., and Weeding, B. (2015). State of the Derwent Estuary: a Review of Environmental Data from 2009 to 2014. Derwent Estuary Program.

Courtene-Jones, W., Quinn, B., Gary, S. F., Mogg, A. O. M., and Narayanaswamy, B. E. (2017). Microplastic pollution identified in deep-sea water and ingested by benthic invertebrates in the Rockall Trough, North Atlantic Ocean. Environ. Pollut. 231(Pt 1), 271-280. doi: 10.1016/j.envpol.2017.08.026

Cózar, A., Echevarría, F., González-Gordillo, J. I., Irigoien, X., Úbeda, B., Hernández-León, S., et al. (2014). Plastic debris in the open ocean. Proc. Natl. Acad. Sci. U.S.A. 111, 10239-10244. doi: 10.1073/pnas.1314705111

Dris, R., Gasperi, J., Rocher, V., Saad, M., Renault, N., and Tassin, B. (2015). Microplastic contamination in an urban area: a case study in Greater Paris. Environ. Chem. 12, 592-599. doi: 10.1071/EN14167

Duckett, P. E., and Repaci, V. (2015). Marine plastic pollution: using community science to address a global problem. Mar. Freshw. Res. 66, 665. doi: 10.1071/MF14087

Endo, S., Takizawa, R., Okuda, K., Takada, H., Chiba, K., Kanehiro, H., et al. (2005). Concentration of polychlorinated biphenyls (PCBs) in beached resin pellets: variability among individual particles and regional differences. Mar. Pollut. Bull. 50, 1103-1114. doi: 10.1016/j.marpolbul.2005.04.030

Eriksen, M., Maximenko, N., Thiel, M., Cummins, A., Lattin, G., Wilson, S., et al. (2013). Plastic pollution in the South Pacific subtropical gyre. Mar. Pollut. Bull. 68, 71-76. doi: 10.1016/j.marpolbul.2012.12.021

Fendall, L. S., and Sewell, M. A. (2009). Contributing to marine pollution by washing your face: microplastics in facial cleansers. Mar. Pollut. Bull. 58, 1225-1228. doi: 10.1016/j.marpolbul.2009.04.025 
Fischer, V., Elsner, N. O., Brenke, N., Schwabe, E., and Brandt, A. (2015). Plastic pollution of the Kuril-Kamchatka Trench area (NW pacific). Deep Sea Res. Part II Top. Stud. Oceanogr. 111, 399-405. doi: 10.1016/j.dsr2.2014.08.012

Galloway, T. S., Cole, M., and Lewis, C. (2017). Interactions of microplastic debris throughout the marine ecosystem. Nat. Ecol. Evol. 1:s41559-41017-40116. doi: 10.1038/s41559-017-0116

Gittman, R. K., and Keller, D. A. (2013). Fiddler crabs facilitate Spartina alterniflora growth, mitigating periwinkle overgrazing of marsh habitat. Ecology 94, 2709-2718. doi: 10.1890/13-0152.1

Green, D. S. (2016). Effects of microplastics on European flat oysters, Ostrea edulis and their associated benthic communities. Environ. Pollut. 216, 95-103. doi: $10.1016 /$ j.envpol.2016.05.043

Gregory, M. R (1977). Plastic pellets on New Zealand beaches. Mar. Pollut. Bull. 8, 82-84. doi: 10.1016/0025-326X(77)90193-X

Horton, A. A., Svendsen, C., Williams, R. J., Spurgeon, D. J., and Lahive, E. (2017). Large microplastic particles in sediments of tributaries of the River Thames, UK-Abundance, sources and methods for effective quantification. Mar. Pollut. Bull. 114, 218-226. doi: 10.1016/j.marpolbul.2016.09.004

Jambeck, J. R., Geyer, R., Wilcox, C., Siegler, T. R., Perryman, M., Andrady, A., et al. (2015). Plastic waste inputs from land into the ocean. Science 347, 768-771. doi: $10.1126 /$ science. 1260352

Klein, S., Worch, E., and Knepper, T. P. (2015). Occurrence and spatial distribution of microplastics in river shore sediments of the rhine-main area in Germany. Environ. Sci. Technol. 49, 6070-6076. doi: 10.1021/acs.est.5b00492

Koehnken, L., and Eriksen, R. (2004). Summary of Derwent Sediment Investigations- Part II, V3. Annex In: DEP (Derwent Estuary Program) 2007. Derwent estuary water quality improvement plan for heavy metals. Prepared by the Derwent Estuary Program with support from the Australian Government coastal catchments initiative, Tasmanian State Government and Derwent Estuary Program partnership.

Law, K. L., Moret-Ferguson, S., Maximenko, N. A., Proskurowski, G., Peacock, E. E., Hafner, J., et al. (2010). Plastic accumulation in the North Atlantic subtropical gyre. Science 329, 1185-1188. doi: 10.1126/science.1192321

Lebreton, L. C., van der Zwet, J., Damsteeg, J.-W., Slat, B., Andrady, A., and Reisser, J. (2017). River plastic emissions to the world's oceans. Nat. Commun. 8:15611. doi: $10.1038 /$ ncomms15611

MacDonald, T. A., Burd, B. J., and Van Roodselaar, A. (2012). Facultative feeding and consistency of trophic structure in marine soft-bottom macrobenthic communities. Mar. Ecol. Prog. Ser. 445, 129-140. doi: 10.3354/meps09478

Magnusson, K., and Norén, F. (2014). Screening of Microplastic Particles In and Down-stream a Wastewater Treatment Plant. IVL Swedish Environmental Research Institute.

Mason, S. A., Garneau, D., Sutton, R., Chu, Y., Ehmann, K., Barnes, J., et al. (2016). Microplastic pollution is widely detected in US municipal wastewater treatment plant effluent. Environ. Poll. 218, 1045-1054. doi: 10.1016/j.envpol.2016.08.056

Masura, J., Baker, J., Foster, G., and Arthur, C. (2015). Laboratory Methods for the Analysis of Microplastics in the Marine Environment: Recommendations for Quantifying Synthetic Particles in Waters and Sediments. ed C. Herring. NOAA Technical Memorandum.

MONAS (2014). Marine Litter in the HELCOM Area: Sources, Monitoring Approaches, Possible Common Indicators and First Lines of Thinking on Measures. Baltic Marine Environment Protection Commission. MONAS.

Morét-Ferguson, S., Law, K.L., Proskurowski, G., Murphy, E.K., Peacock, E.E., and Reddy, C.M. (2010). The size, mass, and composition of plastic debris in the western North Atlantic Ocean. Mar. Pollut. Bull. 60, 1873-1878. doi: 10.1016/j.marpolbul.2010.07.020

PlasticsEurope (2008). The Compelling Facts about Plastics 2007, an Analysis of Plastics Production, Demand and Recovery for 2007 in Europe. Brussels.

PlasticsEurope (2016). Plastics-the Facts 2016: An Analysis of European Plastics Production, Demand and Waste Data.

Reeves, S., Davey, A., and Ling, S. (2016). A Method for Extraction and Enumeration of Microplastics from Marine Sediments: Draft Report. Institute for Marine and Antarctic Studies; University of Tasmania.

Rochman, C. M., Manzano, C., Hentschel, B. T., Simonich, S. L. M., and Hoh, E. (2013). Polystyrene plastic: a source and sink for polycyclic aromatic hydrocarbons in the marine environment. Environ. Sci. Technol. 47, 13976. doi: 10.1021/es403605f

Rochman, C. M., Tahir, A., Williams, S. L., Baxa, D. V., Lam, R., Miller, J. T., et al. (2015). Anthropogenic debris in seafood: plastic debris and fibers from textiles in fish and bivalves sold for human consumption. Sci. Rep. 5:14340. doi: 10.1038/srep14340

Schuyler, Q., Hardesty, B. D., Wilcox, C., and Townsend, K. (2014). Global analysis of anthropogenic debris ingestion by sea turtles. Conserv. Biol. 28, 129-139. doi: $10.1111 /$ cobi.12126

Shiber, J. (1979). Plastic pellets on the coast of Lebanon. Mar. Pollut. Bull. 10, 28-30. doi: 10.1016/0025-326X(79)90321-7

Sruthy, S., and Ramasamy, E. (2017). Microplastic pollution in Vembanad Lake, Kerala, India: the first report of microplastics in lake and estuarine sediments in India. Environ. Pollut. 222, 315-322. doi: 10.1016/j.envpol.2016. 12.038

ter Halle, A., Ladirat, L., Gendre, X., Goudouneche, D., Pusineri, C., Routaboul, C., et al. (2016). Understanding the fragmentation pattern of marine plastic debris. Environ. Sci. Technol. 50, 5668-5675. doi: 10.1021/acs.est. 6 b00594

Teuten, E. L., Rowland, S. J., Galloway, T. S., and Thompson, R. C. (2007). Potential for plastics to transport hydrophobic contaminants. Environ. Sci. Technol. 41, 7759-7764. doi: 10.1021/es071737s

Thompson, R. C., Moore, C. J., vom Saal, F. S., and Swan, S. H. (2009). Plastics, the environment and human health: current consensus and future trends. Philos. Trans. R. Soc. B Biol. Sci. 364, 2153-2166. doi: 10.1098/rstb.2009.0053

Thompson, R. C., Olsen, Y., Mitchell, R. P., Davis, A., Rowland, S. J., John, A. W. G., et al. (2004). Lost at sea: where is all the plastic? Science 304, 838-838. doi: 10.1126/science.1094559

Townsend, A. T., and Seen, A. J. (2012). Historical lead isotope record of a sediment core from the Derwent River (Tasmania, Australia): a multiple source environment. Sci. Total Environ. 424, 153-161. doi: 10.1016/j.scitotenv.2012.02.011

Van Cauwenberghe, L., and Janssen, C. R. (2014). Microplastics in bivalves cultured for human consumption. Environ. Pollut. 193, 65-70. doi: 10.1016/j.envpol.2014.06.010

Van Cauwenberghe, L., Vanreusel, A., Mees, J., and Janssen, C. R. (2013). Microplastic pollution in deep-sea sediments. Environ. Pollut. 182, 495-499. doi: 10.1016/j.envpol.2013.08.013

van Sebille, E., Wilcox, C., Lebreton, L., Maximenko, N., Hardesty, B. D., van Franeker, J. A., et al. (2015). A global inventory of small floating plastic debris. Environ. Res. Lett. 10:124006. doi: 10.1088/1748-9326/10/12/ 124006

Vianello, A., Boldrin, A., Guerriero, P., Moschino, V., Rella, R., Sturaro, A., et al. (2013). Microplastic particles in sediments of Lagoon of Venice, Italy: first observations on occurrence, spatial patterns and identification. Estuar. Coast. Shelf Sci. 130, 54-61. doi: 10.1016/j.ecss.2013.03.022

Wilcox, C., Van Sebille, E., and Hardesty, B. D. (2015). Threat of plastic pollution to seabirds is global, pervasive, and increasing. Proc. Natl. Acad. Sci. U.S.A. 112, 11899-11904. doi: 10.1073/pnas.1502108112

Willis, K., Hardesty, B. D., Kriwoken, L., and Wilcox, C. (2017). Differentiating littering, urban runoff and marine transport as sources of marine debris in coastal and estuarine environments. Sci. Rep. 7:44479. doi: 10.1038/srep44479

Woodall, L. C., Gwinnett, C., Packer, M., Thompson, R. C., Robinson, L. F., and Paterson, G. L. (2015). Using a forensic science approach to minimize environmental contamination and to identify microfibres in marine sediments. Mar. Pollut. Bull. 95, 40-46. doi: 10.1016/j.marpolbul.2015.04.044

Woodall, L. C., Sanchez-Vidal, A., Canals, M., Paterson, G. L., Coppock, R., Sleight, V., et al. (2014). The deep sea is a major sink for microplastic debris. R. Soc. Open Sci. 1:140317. doi: 10.1098/rsos.140317

Zobkov, M., and Esiukova, E. (2017). Microplastics in Baltic bottom sediments: quantification procedures and first results. Mar. Pollut. Bull. 114, 724-732. doi: 10.1016/j.marpolbul.2016.10.060

Conflict of Interest Statement: The authors declare that the research was conducted in the absence of any commercial or financial relationships that could be construed as a potential conflict of interest.

Copyright (C) 2017 Willis, Eriksen, Wilcox and Hardesty. This is an open-access article distributed under the terms of the Creative Commons Attribution License (CC BY). The use, distribution or reproduction in other forums is permitted, provided the original author(s) or licensor are credited and that the original publication in this journal is cited, in accordance with accepted academic practice. No use, distribution or reproduction is permitted which does not comply with these terms. 